\title{
Fasting Enhances Growth Hormone Secretion and Amplifies the Complex Rhythms of Growth Hormone Secretion in Man
}

\author{
Kian Y. Ho, “ Johannes D. Veldhuis, “ Michael L. Johnson, ${ }^{\ddagger}$ Richard Furlanetto, ${ }^{5}$ William S. Evans, \\ K. G. M. M. Alberti," and Michael O. Thorner* \\ Departments of ${ }^{*}$ Internal Medicine and ${ }^{\ddagger}$ Pharmacology, University of Virginia Medical School, Charlottesville, Virginia 22908; \\ ${ }^{\S}$ The Childrens Hospital of Philadelphia, University of Pennsylvania, Philadelphia, Pennsylvania 19104; \\ and "the Royal Victoria Infirmary, Newcastle Upon Tyne, England
}

\begin{abstract}
Studies in man have shown that the episodic release of growth hormone (GH) is infrequent and erratic, and unlike that in the rat does not appear to have discernible ultradian periodicities. However, these observations in nonfasted subjects may be invalid since mixed nutrients have unpredictable effects on $\mathbf{G H}$ release. Moreover, in the fed state basal GH levels are frequently undetectable, thus rendering the identification of low amplitude pulses unreliable. Accordingly, the 24-h pulsatile pattern of $\mathbf{G H}$ secretion obtained from repetitive venous sampling in six normal adult male subjects was examined during a control fed day and during the first and fifth days of a 5-d fast. The GH data were analyzed using two distinct methods: a discrete pulse detection algorithm (Cluster analysis) and Fourier expansion time-series, which allows fixed periodicities of secretory activity to be resolved. The 5-d fast resulted in a significant increase in discrete $\mathbf{G H}$ pulse frequency $(5.8 \pm 0.7$ vs. 9.9 \pm 0.7 pulses $/ 24 \mathrm{~h}, P=0.028), 24 \mathrm{~h}$ integrated $\mathrm{GH}$ concentration (2.82 \pm 0.50 vs. 8.75 $\pm 0.82 \mu \mathrm{g} \cdot \mathrm{min} / \mathrm{ml} ; P=0.0002)$, and maximal pulse amplitude $(5.9 \pm 1.1 \mathrm{vs} .12 .3 \pm 1.6 \mathrm{ng} / \mathrm{ml}, P$ $<0.005)$. While multiple low-amplitude sinusoidal periodicities were present on the control fed day, time-series analysis revealed enhancement of circadian and ultradian cycles on the first and fifth days of fasting. Concomitantly, fasting resulted in a decline (day 1 vs. day 5) in serum concentrations of somatomedin $C(1.31 \pm 0.22$ vs. $0.77 \pm 0.18 \mathrm{U} / \mathrm{ml})$ and glucose (4.9 \pm 0.2 vs. $3.2 \pm 0.2 \mathrm{mmol} / \mathrm{liter})$, and a marked rise in free fatty acid (0.43 $\pm 0.12 \mathrm{vs}$. $1.55 \pm 0.35 \mathrm{mmol} / \mathrm{liter})$ and acetoacetate (35 \pm 6 vs. $507 \pm 80 \mathrm{nmol} /$ liter).

We conclude that the acute nutritional status is an important determinant of spontaneous pulsatile GH secretion in man. Fast-induced enhancement of GH release is achieved through combined frequency (discrete pulses) and amplitude (sinusoidal periodicities) modulation. Such alterations in somatotropic hormone release may play an important role in substrate homeostasis during starvation.
\end{abstract}

\section{Introduction}

Growth hormone (GH) ${ }^{1}$ is secreted episodically in man. Although it is well established that $\mathrm{GH}$ release is entrained to the

This work was presented in part at the 68th Annual Meeting of the Endocrine Society, Anaheim, CA, 25-27 June 1986.

Received for publication 2 February 1987 and in revised form 16 November 1987.

1. Abbreviations used in this paper: GH, growth hormone; GHRH,

J. Clin. Invest.

(c) The American Society for Clinical Investigation, Inc.

0021-9738/88/04/0968/08 \$2.00

Volume 81, April 1988, 968-975 onset of slow-wave sleep $(1,2)$, at other times during the day release is intermittent, erratic, and unpredictable with no recognizable pattern or periodicity (3-8). This stands in contrast to the rat that possesses an ultradian pattern characterized by rhythmic release of GH approximately every 3-4 h (9). Thus, in man, GH release is nyctohemeral and does not appear to display distinct cyclic ultradian periodicity throughout the 24-h period.

Different nutrients have different effects on $\mathrm{GH}$ release. For example, glucose and fatty acids suppress $\mathrm{GH}$ release while certain amino acids stimulate secretion (10). Most of the 24-h studies of $\mathrm{GH}$ secretion to date have been carried out in the fed state (3-6, 8). Accordingly, inferences regarding the absence of demonstrable cyclic periodicity in man may not be valid because of the unpredictable effects of mixed nutrients. In addition, basal GH concentrations in the fed state are frequently undetectable by conventional radioimmunoassay, thus rendering the identification of small pulses impossible or unreliable.

Fasting would be expected to eliminate the unpredictable effects of mixed nutrients on GH secretion. Moreover, fasting lowers somatomedin $\mathrm{C}$ levels (11) and in so doing removes feedback inhibition of $\mathrm{GH}$ release (12). This open-loop system would be predicted to elevate basal $\mathrm{GH}$ concentrations and allow identification of spontaneous pulsatility with greater accuracy.

In view of the preceding considerations, our aim was to determine the serial effects of fasting on the 24-h pulsatile pattern of GH secretion in man. We hypothesized that the otherwise concealed characteristics of periodic GH secretion might be uncovered by fasting. We employed an immunoradiometric assay with enhanced sensitivity for the measurement of $\mathrm{GH}$ and characterized the episodic pattern of $\mathrm{GH}$ secretion using two distinct methods: a discrete, statistically based, pulse detection algorithm, and the Fourier expansion time-series. These two approaches are able to resolve episodic pulsations and regularly recurring periodicities, respectively. Since pituitary $\mathrm{GH}$ release is in part dependent on hypothalamic GH-releasing hormone (GHRH) secretion $(13,14)$, we administered GHRH-40 at the end of each 24-h study period to ascertain whether altered responsiveness to GHRH accompanied changes in $\mathrm{GH}$ release during fasting.

\section{Methods}

\section{Subjects}

Six normal healthy male volunteers (ages 21-36 yr) of normal body weight (BMI $21.8-28.0 \mathrm{~kg} / \mathrm{m}^{2}$ ) were studied. Each subject gave written informed consent, approved by the Human Investigation Committee

growth hormone-releasing hormone; IGHC, integrated growth hormone concentration; SmC, somatomedin C. 
of the University of Virginia School of Medicine. All subjects had normal sleep habits, had not taken any transmeridian flights within the previous 4 wk, and were not taking any medication.

\section{Study design}

Each subject was studied on three occasions during which blood samples were obtained every 20 min over a $24-h$ period. These studies were undertaken during $(a)$ a control fed day, in which three meals were served at 0900,1300 , and 1800 hours, and on $(b)$ the first and $(c)$ fifth days of a 5-d fast in which only water, potassium chloride $(20 \mathrm{meq} / \mathrm{d})$, and vitamin supplements ( 1 multivitamin capsule/d) were given. In three subjects, the control fed study was performed before the two fasted studies, while in the remaining three, the control study was undertaken last. A period of 2 wk separated the fed and the fasted studies. The subjects were admitted to the Clinical Research Center at 0700 hours and a cannula with a heparin lock was inserted into a forearm vein. A 1-h period was allowed before commencement of the studies at 0800 hours. Subjects were encouraged to ambulate on study days and daytime naps were prohibited. Sleeping was permitted after 2200 hours and the period of sleep recorded by the ward staff. An intravenous bolus dose of $1 \mu \mathrm{g} / \mathrm{kg}$ GHRH- 40 was administered at the end of each of the three 24-h studies, and blood sampling continued at the same frequency for a further $3 \mathrm{~h}$. Blood samples for glucose, free fatty acids, $\beta$-hydroxybutyrate, acetoacetate, somatomedin $\mathrm{C}(\mathrm{SmC})$, and blood biochemistries were obtained during the 5-d fast. Subjects were also weighed daily and a urine analysis performed daily for urinary ketones.

\section{Assays}

Samples from each individual's three studies $(n=72+9$ for each study) were run in triplicate in the same assay. $\mathrm{GH}$ was measured using the Nichols Institute (San Juan Capistrano, CA) hGH immunoradiometric assay which was modified to enhance the limit of sensitivity to $0.2 \mathrm{ng} / \mathrm{ml}$. The intraassay coefficients of variation were $6.3,6.4$, and $3.9 \%$ at $4,7.3$, and $19.8 \mathrm{ng} / \mathrm{ml}$, respectively. The interassay coefficients of variation were $<9.2 \%$ at the above levels. Blood glucose was measured using the glucose oxidase method and a glucose analyzer (Beckman Instruments, Fullerton, CA) (15). SmC, unesterified fatty acids, acetoacetate, and $\beta$-hydroxbutyrate concentrations were measured using methods as previously described $(16,17)$ and as adapted from reference 18 .

\section{Data analysis}

Two distinct mathematical methods were used to characterize the effects of fasting on episodic $\mathrm{GH}$ secretion.

Pulse analysis. Discrete GH pulses were identified using Cluster analysis, an objective multipoint, statistically based pulse detection algorithm that defines significant hormone excursions in relation to the actual experimental variance (19). A pulse is defined as a statistically significant increase in a cluster of hormone values followed by a statistically significant decrease in a second cluster of values. Based upon prior objective optimization studies, the cluster size for nadirs and peaks (the number of points used in testing nadirs against peaks) was set at 1 and 2, respectively (20). Pulse criteria were set to minimize the occurrence of false positive pulses on signal-free noise to $<5 \%$. Identified properties of pulsatile $\mathrm{GH}$ release included: pulse frequency, maximal peak amplitude, mean interpulse GH concentrations, integrated GH concentration (IGHC or area under the curve), and the fraction of $\mathrm{GH}$ secreted in pulses.

Time-series analysis of periodic hormone release. Serial GH data were also analyzed for the occurrence of significant sinusoidal periodicities using transformation, as described previously (21). Since the Fourier series is a linear combination of terms, the standard deviations of the individual coefficients can be determined by linear least-squares estimation models (22). Using within-sample variance from all experimental replicates, this approach permits one to define all individual significant periodicities (as sine or cosine functions) and estimate their corresponding amplitudes with statistical confidence limits. An un- derlying periodicity in the data was considered significant whenever its amplitude exceeded zero by at least $1.96 \mathrm{SD}(P<0.025$ at each tail $)$ compared with signal-free noise. Only such periodicities were considered further.

Statistical analysis. Paired two-tailed $t$-statistics were used to test for significant changes in the means of parameters measured during control and fasting sessions. Results are expressed as mean \pm SEM.

\section{Results}

The six subjects lost a mean of $4.8 \pm 0.3 \mathrm{~kg}$ during the $5 \mathrm{~d}$ of fasting. Fig. 1 shows changes in blood glucose, free fatty acids, $\beta$-hydroxybutyrate, and acetoacetate concentrations during the 5-d fast. There was a progressive fall $(P<0.0002)$ in blood glucose from $4.9 \pm 0.2 \mathrm{mmol} / \mathrm{liter}(88 \pm 3 \mathrm{mg} / \mathrm{dl})$ to $3.2 \pm 0.2$ $\mathrm{mmol} / \mathrm{liter}(57 \pm 3 \mathrm{mg} / \mathrm{dl})$. Fasting resulted in a fivefold increase in free fatty acid levels $(0.43 \pm 0.12 \mathrm{mmol} / \mathrm{liter}$ to $1.55 \pm 0.35 \mathrm{mmol} /$ liter), a 14 -fold rise in acetoacetate concentrations ( $35 \pm 6$ to $507 \pm 80 \mathrm{nmol} /$ liter) and a greater than sixtyfold increase in $\beta$-hydroxybutyrate concentrations ( $57 \pm 10$ to $3,945 \pm 659 \mathrm{nmol} /$ liter).

There was a slow but progressive decline in circulating SmC concentrations with increasing duration of fast. The changes in SmC were significant by the fifth fasted day $(0.77 \pm 0.18$ vs. $1.31 \pm 0.22 \mathrm{U} / \mathrm{ml}$ on day $1 ; P<0.02)$.

The 24-h IGHC (micrograms per minute per milliliter) increased after $1 \mathrm{~d}$ of fasting $(2.82 \pm 0.50$ vs. $7.82 \pm 1.12$, control vs. day $1 ; P=0.0009$ ) and remained elevated on day 5 $(8.75 \pm 0.82)$. The pulsatile component (Fig. 2) of GH release followed a similar pattern with an increase on day 1 (2.07 \pm 0.47 vs. $5.74 \pm 0.78$, control vs. day $1 ; P=0.0013)$ but no further increase on day $5(4.25 \pm 0.67)$. In contrast, although there was a strong trend in the nonpulsatile component of $\mathrm{GH}$ release to increase on day 1 , no significant change was noted $(0.75 \pm 0.11$ vs. $2.08 \pm 0.53$, control vs. day $1 ; P=0.10)$. By day 5 , however, nonpulsatile $\mathrm{GH}$ release was markedly enhanced (4.50 $\pm 0.75 ; P=0.0002$ ).

Fasting also resulted in a progressive increase in mean $\mathrm{GH}$ pulse frequency and maximal pulse amplitude. The mean number of peaks per $24 \mathrm{~h}$ increased from $5.8 \pm 0.7$ to $7.3 \pm 0.6$ $(P<0.004)$ on the first fasted day and to $9.9 \pm 0.7(P<0.03)$ on the fifth fasted day. There was also a significant increase in the mean maximal GH peak amplitude between the control day $(5.9 \pm 1.1 \mathrm{ng} / \mathrm{ml})$ and the first fasted day $(13.1 \pm 1.2 \mathrm{ng} / \mathrm{ml}, P$ $=0.003)$ and the fifth fasted day $(12.3 \pm 1.6 \mathrm{ng} / \mathrm{ml}, P=0.005)$. The mean interpeak GH concentrations were mostly below

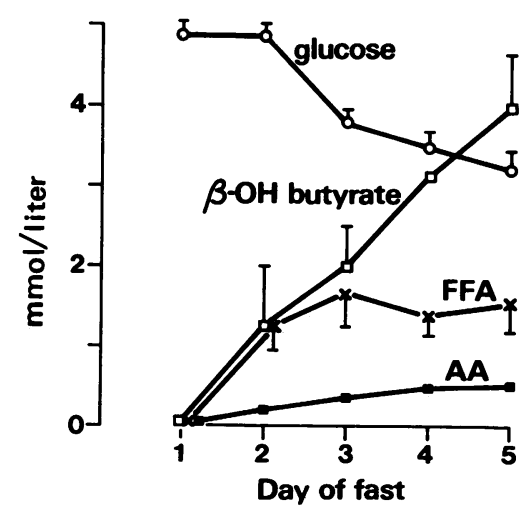

Figure 1. Changes in the mean \pm SEM blood glucose, free fatty acid (FFA), $\beta$-hydroxybutyrate $(\beta-\mathrm{OH})$, and acetoacetate (AA) concentrations during $5 \mathrm{~d}$ of fasting $(n=6)$. Sample on day 1 is drawn after overnight fast, i.e., under identical conditions for control fed day. 


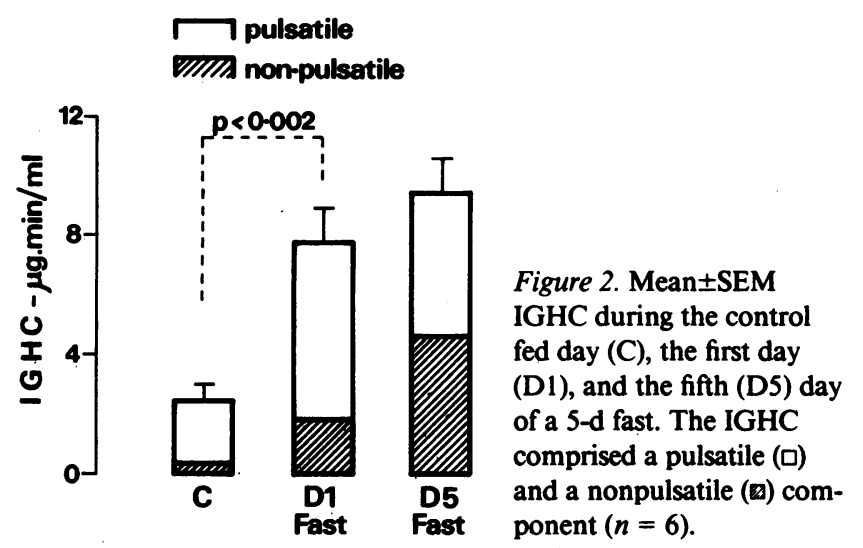

the limit of assay detection on the control fed day $(0.3 \pm 0.2$ $\mathrm{ng} / \mathrm{ml}$ vs. $1.3 \pm 0.5 \mathrm{ng} / \mathrm{ml}$ on the first fasted day, $P=0.04)$ and increased to $3.4 \pm 0.8 \mathrm{ng} / \mathrm{ml}$ on the fifth fasted day $(P=0.007$ vs. control; $P=0.03$ vs. day 1 ). With the increase in interpulse GH concentrations incremental GH peak amplitude (difference between peak nadir and maximum) increased from $5.7 \pm 1.0 \mathrm{ng} / \mathrm{ml}$ to $11.9 \pm 1.1(P=0.006)$, then fell back to $8.6 \pm 1.3 \mathrm{ng} / \mathrm{ml}(P=\mathrm{NS}$, day 1 vs. day 5). In Fig. 3 the amplified patterns of $\mathrm{GH}$ secretion induced by fasting and responses to GHRH-40 are shown in all six subjects. Table I summarizes the specific changes in individual peak properties quantitated in each of the six subjects on the $3 \mathrm{~d}$ of study.

To look for regular underlying sinusoidal periodicities of GH secretion, we subjected the data to time-series analysis for each of the study days. Fig. 4 shows such an analysis in a representative subject for whom amplitudes of the Fourier transformations are plotted against periodicity in minutes. No single dominant periodicity is present during the control fed day as reflected in the flat profile of the periodogram; however, many significant ultradian rhythms existed on the control day. On the first fasted day, this subject's periodogram shows the presence of three higher amplitude cycles, one with a periodicity of $\sim 90-100 \mathrm{~min}$, the second with a periodicity of $\sim$ 180-240 min, and the third displaying the circadian fundamental rhythmicity of $24 \mathrm{~h}(1,440 \mathrm{~min})$. The mean amplitudes of the Fourier transforms for the six men on the control fed day were compared with those on each of the two fasted days (Fig. 5). This analysis revealed that fasting for $1 \mathrm{~d}$ evoked significantly $(P<0.025)$ higher amplitude cycles with periodicities of $1,440,243,145$, and $91 \mathrm{~min}$, whereas fasting for $5 \mathrm{~d}$ evoked significantly higher amplitude cycles above the fed state with periodicities of $1,440,91,70$, and $44 \mathrm{~min}$. It should be noted, as discussed below, that the 90-min and circadian periods were the only ones to be amplified significantly above the fed state on each of the fasting days. For example, the mean circadian (1,440 $\mathrm{min}$ ) $\mathrm{GH}$ amplitudes were $1.7 \mathrm{ng} / \mathrm{ml}$ (fed), 3.9 $\mathrm{ng} / \mathrm{ml}$ (fasting day 1 ), and $3.7 \mathrm{ng} / \mathrm{ml}$ (fasting day 5 ). The data show increased amplitudes of a number of higher frequency cycles on the two fasted days in conjunction with a periodicity of $1,440 \mathrm{~min}(24 \mathrm{~h})$.

The mean maximal GH levels obtained after GHRH administration after the first fasted day $(38.3 \pm 9.5 \mathrm{ng} / \mathrm{ml})$ and the fifth fasted day $(35.0 \pm 6.0 \mathrm{ng} / \mathrm{ml})$ were not significantly different from that obtained on the control fed day $(26.2 \pm 6.9$ $\mathrm{ng} / \mathrm{ml}$ ). The time courses of the GH responses to GHRH under these three conditions are given graphically in Fig. 3. Further analyses using integrated GHRH-stimulated GH data by parametric and nonparametric testing also indicated the absence of significant differences in GHRH responses with fasting.

\section{Discussion}

The present studies in man show that fasting results in distinct quantitative and qualitative amplification of the 24-h pattern of GH secretion. The use of two independent methods-a discrete, statistically based, pulse detection algorithm and time-series analysis-reveals that these changes are accomplished by both frequency and amplitude modulation of pulsatile GH secretion. Furthermore, time-series analyses disclosed for the first time increased amplitudes of a circadian rhythm and consistent underlying noncircadian rhythms with periodicities of $\sim 44-243 \mathrm{~min}$ on days 1 and 5 of fasting. The uniformity of a 90-min cycle on both fasted days suggests the presence of an intrinsic 90-min ultradian rhythm associated with the release of $\mathrm{GH}$ in man. A number of other $\mathrm{GH}$ cycles were also present on the fed (control) day and amplified on the first and fifth days of nutrient deprivation. At present, the exact physiological significance and/or neural origin of these cycles is not known.

Our results indicate that the 24-h secretory pattern of GH in man is complex, since it represents the composite of several apparently periodic cycles (ultradian and circadian) as well as nonrhythmic GH discharges (discrete pulses) arising from environmental cues or factors not identifiable under the conditions of the study. Moreover, unlike the distinct basal periodicity of $3.3 \mathrm{~h}$ in the rat (9) or $4.1 \mathrm{~h}$ in the baboon (23), a single dominant underlying ultradian rhythm in man was not discernible in the basal state.

Previous studies of GH rhythmicity in man have not demonstrated significant periodic rhythms. Extensive studies performed by Parker et al. (2) involving 20-min sampling in the fed state suggested the presence of frequency components of two to five cycles per day, which the authors postulated to be meal-cued events (2). In less intensive sampling studies carried out in the fasted state, these investigators noted an enhancement of pulse frequency associated with new frequencies having a periodicity of $\sim 3 \mathrm{~h}(24)$. We postulate that the 3-h periodicity is a harmonic of the more fundamental $90-\mathrm{min}$ rhythm identified by fasting in the present study, and that the failure to detect a more rapid fundamental periodicity may be due to the use of a less intensive sampling interval of $30 \mathrm{~min}$. In this regard, even more intensive sampling than that carried out in the present studies might ultimately further disclose the full spectrum of unrestrained ultradian $\mathrm{GH}$ periodicities in man.

The finding of ultradian cyclical events for GH bears striking similarity to the circhoral rhythmicity observed for luteinizing hormone release. In man, a number of behavioral and neuromuscular functions have a similar cycle of occurrence. These include rapid eye movement sleep (25), dreaming and penile tumescence (26), blood pressure variations (27), telemetered gross body activity (28), oral intake activity (29), and plasma norepinephrine concentrations (30). Though ostensi- 


\section{CONTROL}
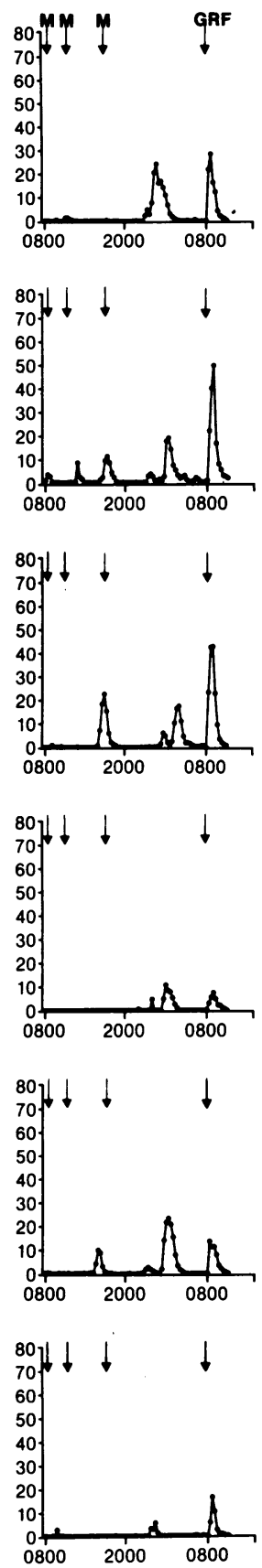
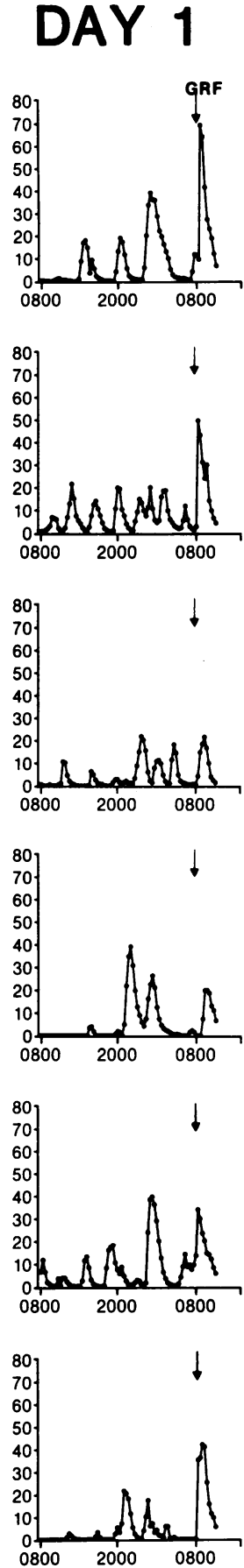

TIME (Hours)
DAY 5
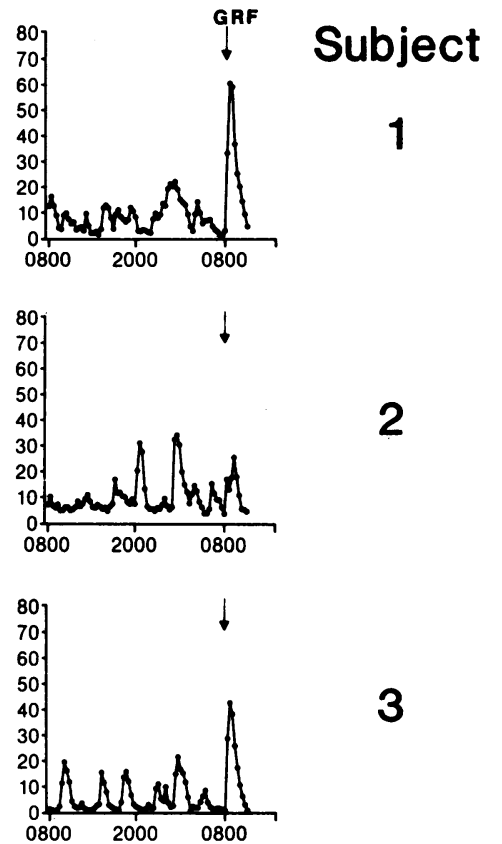

3

2

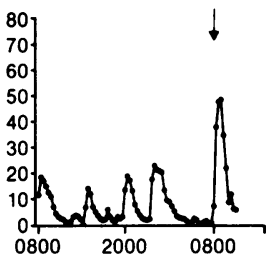

4

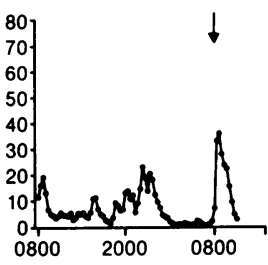

5

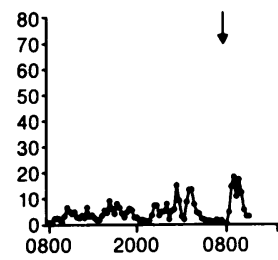

6

Figure 3. 24-h GH profiles for all six subjects during control fed day (left), the first fasted day (middle), and fifth fasted day (right). $\mathbf{M}$ denotes meal times; GRF denotes intravenous injection of $1 \mu \mathrm{g} / \mathrm{kg}$ GHRH (1-40)-OH.

bly unrelated, these synchronous secretory and motor events suggest the existence of a central primary oscillator to which these systems are coupled directly or indirectly.

The neuroendocrine mechanisms governing the rhythmic discharge of $\mathrm{GH}$ in the rat are resistant to the acute effects of feeding, hyperglycemia, and insulin-induced hypoglycemia (31). More sustained changes induced by starvation or by streptozotocin-induced diabetes mellitus have profound effects on GH secretion in the rat $(32,33)$. However, in the rat these two perturbations suppress rather than augment $\mathrm{GH}$ secretion. Thus, our observations underscore the importance of studying man to understand the physiology of human GH. In addition, the difference in regulation of GH may reflect its different metabolic roles in the rat when compared with the human. This may also result from the rat's inherent pattern of continuous feeding when compared with the human pattern of one to three meals per day.

Although insulin plays a pivotal role in the hormonal con- 
trol of metabolic adaptation during fasting, the relative importance of other hormones such as $\mathrm{GH}$, glucagon, and cortisol remains controversial $(34,35)$. The known ability of $\mathrm{GH}$ to increase hepatic glucose output $(36,37)$, to promote positive nitrogen balance $(38)$, and to induce lipolysis $(39,40)$ suggests that it should have an important role in partitioning metabolic fuels to conserve protein during starvation. A number of studies, however, have questioned its physiological importance in fasting. First, GH levels were reported to show great variability, to be only inconsistently elevated during fasting, and more importantly to mirror inadequately changes in substrate concentrations during starvation $(35,41,42)$. The GH secretory status in those studies, however, was defined from random single blood samples drawn usually on the morning of each fasted day. The marked pulsatile nature of GH secretion observed during our fasting studies clearly indicates that a single random sample cannot provide a reliable estimate of overall 24-h secretion. Secondly, GH administration failed to decrease urine nitrogen loss during starvation in normal or in GH-deficient subjects $(35,40,41)$. However, the anabolic or nitrogenretaining effects are indirect and are thought to be mediated by the generation of tissue growth factors such as SmC. Our data demonstrate that fasting causes a dissociation between increased GH secretion and SmC production. Thus, anabolic effects of $\mathrm{SmC}$ would have been minimal during starvation since circulating (and presumably tissue) concentrations of this growth factor were low.

Our data also show that circulating $\mathrm{SmC}$ concentrations are strongly governed by nutrition, confirming the important observations of Clemmons et al. (11). It can be inferred that nutrient sufficiency is a more important determinant of SmC than $\mathrm{GH}$, since the concentration of this growth factor failed to rise in the face of enhanced GH secretion. Such observations emphasize the importance of nutrition in dictating the metabolic effects of $\mathrm{GH}$. The presence of a nutrition-dependent component of GH action would be beneficial to man since anabolic processes can proceed only in the presence of adequate nutrition.

The current known actions of GH support the view that augmented GH secretion provides two levels of defense against starvation. The first relates to the maintenance of glucose supply through an increase in hepatic glucose production and the second, the provision of an alternative energy source by increasing fat mobilization and oxidation, thereby indirectly sparing body protein (43). While the increase in integrated $\mathrm{GH}$ concentrations had occurred by the first fasted day, there was a further increase in the nonpulsatile component of $\mathrm{GH}$ release from fourfold on the first fasted day to 10-fold on the fifth fasted day. We speculate that these qualitative changes in the patterns of GH release may play a role in mediating the welldocumented switch from a predominantly gluconeogenic to a lipolytic source of metabolic fuel with prolongation of fasting. Studies addressing possible differential actions of $\mathrm{GH}$ as a function of the signal mode (continuous vs. pulsatile) have not been undertaken in man. It has been recently reported that the secretory pattern of GH regulates fatty acid composition of phosphatidylcholine in the plasma and liver of the rat (44) and that a feminine secretory pattern of GH induces high serum levels of corticosteroid binding globulin in the rat (45).

The neuroendocrine mechanisms regulating $\mathrm{GH}$ secretion appear to be exquisitely sensitive and responsive to nutritional

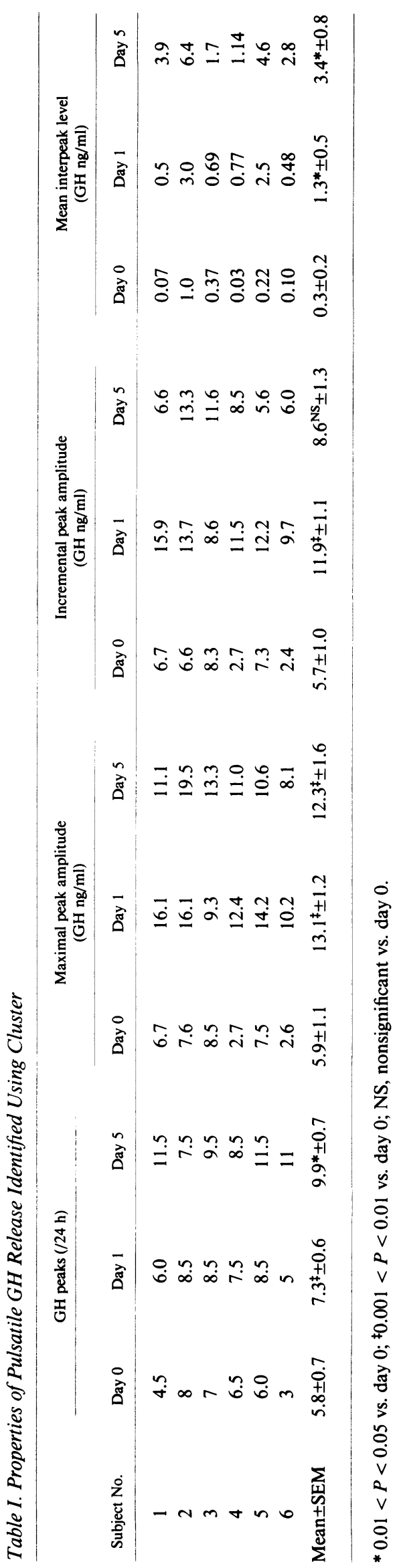




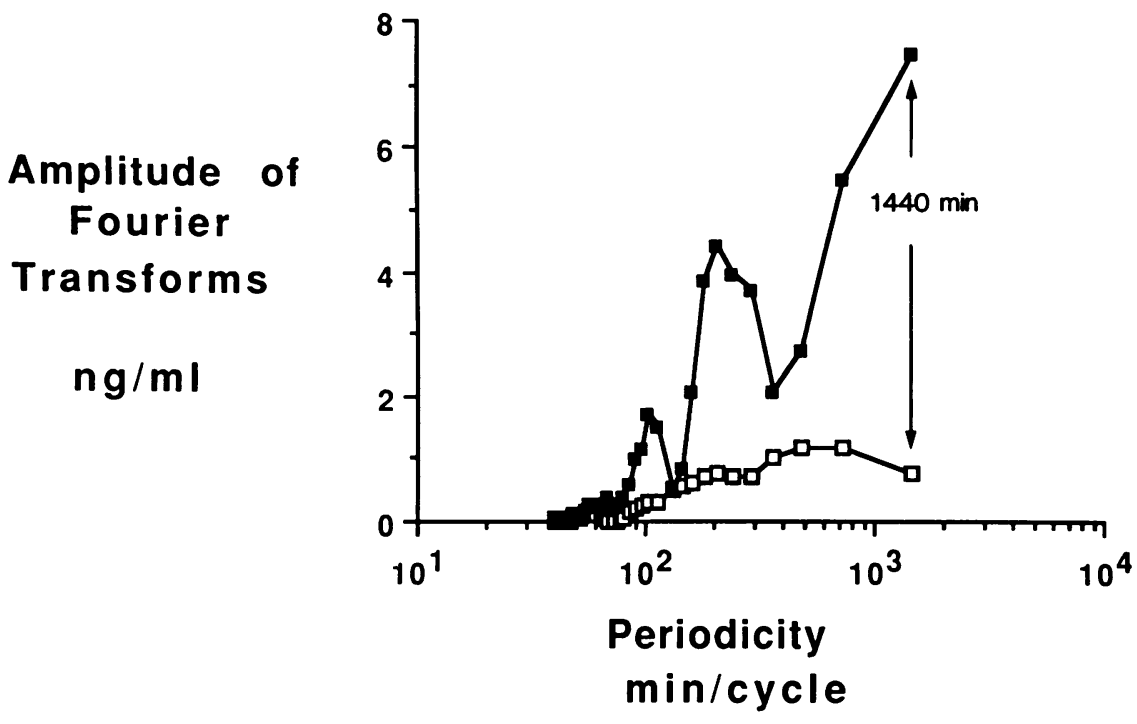

Figure 4. Amplitudes of the Fourier transformations (sine and cosine expansion) of the GH series from a representative subject obtained during the control fed day ( $\square$ ) and during the first day of fasting ( $\square$ ). The horizontal axis shows the periodicities (minutes per cycle) on a logarithmic scale and the vertical axis the amplitudes (nanograms per milliliter) of the significant Fourier transformations. Note the presence of three high amplitude cycles with periodicities of 110 and $206 \mathrm{~min}$ and $24 \mathrm{~h}$ on the first fasted day. status in man. It is unclear, however, what factors specifically activate this system at the onset of fasting. Circulating glucose and $\mathrm{SmC}$, both known inhibitors of $\mathrm{GH}$ secretion, are possible candidates but considered unlikely since a decline in their respective concentrations had not occurred when there was a

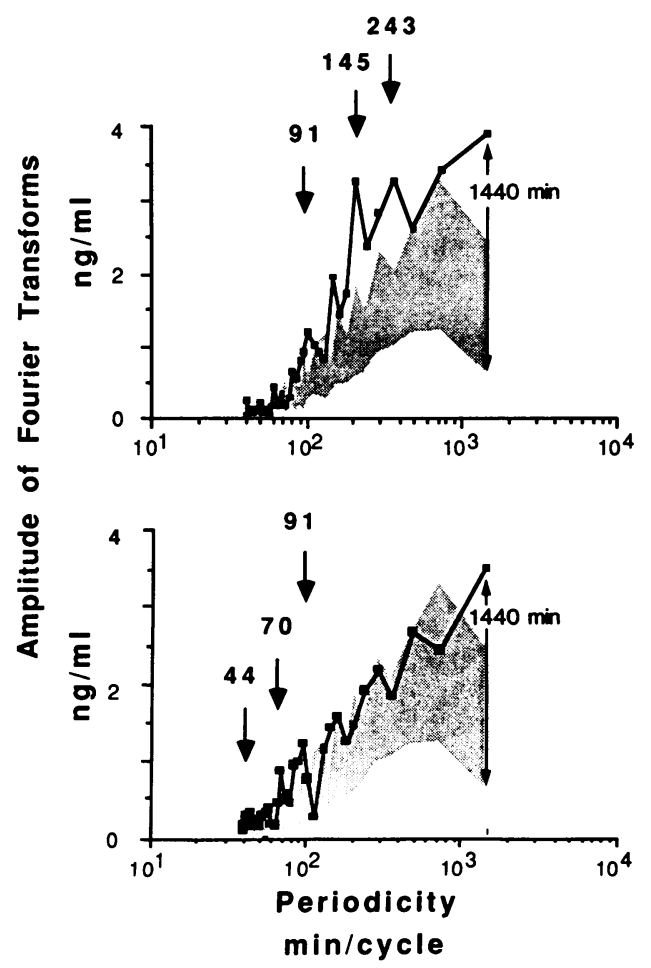

Figure 5. Mean of the amplitudes of the significant Fourier transformations of the GH series of the six normal males obtained during the first (top) and the fifth (bottom) days of fasting. The shaded region shows the mean \pm 2 SD of the significant amplitudes of the Fourier transformation obtained during the control fed day. Significantly higher amplitude cycles of certain fixed periodicities are present on the first (91-, 145-, and 243-min periodicities) fasted day and on the fifth (44-, 70-, and 91-min periodicities) fasted day. threefold increase in total GH secretion (during the first fasted day). However, we cannot exclude the possibility that a small decline in tissue concentrations of SmC occurred in the hypothalamus or pituitary gland. Our results do indicate that since the $\mathrm{GH}$ responses to GHRH did not change with fasting, enhanced spontaneous $\mathrm{GH}$ secretion is unlikely to be due to marked alterations in somatotrope responsiveness to hypothalamic GHRH. Rather, a variety of factors, including enhanced hypothalamic GHRH secretion and/or reduced somatostatin secretion, may be involved. Although acute infusions of free fatty acids inhibit GH secretion (46), the effects of many metabolites, including for example $\beta$-hydroxybutyrate and acetoacetate, on GH secretion are unknown. The possibility that enhanced pulsatile $\mathrm{GH}$ secretion during fasting may result from feedback (positive or negative) of these metabolite(s) on GHRH and somatostatin release has not been investigated. However, caution should be exercised, as acute changes may produce different effects on GH secretion when compared with chronic changes. In addition, interactions between metabolites may be vital.

In summary, the present study demonstrates that the nutritional state is a major determinant of spontaneous rhythmic $\mathrm{GH}$ secretion in man. Although $5 \mathrm{~d}$ of fasting might be considered unphysiological, fasting for $12-24 \mathrm{~h}$ is common for most animal species and primitive man. Accordingly, the choice of well-fed industrialized man as a model to study the pulsatile properties of $\mathrm{GH}$ release may therefore be inappropriate, and may explain why an ultradian pattern of secretion had not been demonstrated previously.

\section{Acknowledgments}

We are grateful to Mrs. Sandra Jackson and her nursing staff of the Clinical Research Center of the University of Virginia for excellent clinical assistance. We thank Mr. Anthony Amos, Ms. Catherine Cassada, and Ms. Carole Weishart for excellent technical assistance; Dr. Elisabeth Christiansen and Dr. Amilton Faria for assistance in GH pulse analysis; and Mrs. Donna Harris and Mrs. Suzan Pezzoli for assistance in preparation of the manuscript. 
This work was supported by U.S. Public Health Service grants GCRC and CLINFLO RR 00847, DK 32632 (Dr. Thorner), RCDA 1 K04 HD-00634 (Dr. Veldhuis), RCDA 1K04 HD-00711 (Dr. Evans), and Biomathematics Core DRTC AM 22125. Dr. Ho was supported by a grant from the Medical Foundation, University of Sydney and the Royal Australasian College of Physicians.

\section{References}

1. Takahashi, Y., D. M. Kipnis, and W. H. Daughaday. 1968. Growth hormone secretion during sleep. J. Clin. Invest. 47:20792090.

2. Parker, D. C., L. G. Rossman, D. F. Kripke, W. Gibson, and K. Wilson. 1979. Rhythmicities in human growth hormone concentrations in plasma. In Endocrine Rhythms. D. T. Krieger, editor. Raven Press, New York. 143-173.

3. Finkelstein, J. W., H. P. Roffwang, R. M. Boyar, J. Kream, and L. Hellman. 1972. Age-related change in the twenty-four hour spontaneous secretion of growth hormone. J. Clin. Endocrinol. \& Metab. 35:665-670.

4. Goldsmith, S. J., and S. M. Glick. 1970. Rhythmicity of growth hormone secretion. Mt. Sinai J. Med. (NY). 4:501-509.

5. Ho, K. Y., W. S. Evans, R. M. Blizzard, J. D. Veldhuis, G. R. Merriam, E. Samojilik, R. Furlanetto, A. D. Rogol, D. L. Kaiser, and M. O. Thorner. 1987. Effects of sex and age on the 24 hour secretory profile of GH secretion in man: importance of endogenous estradiol concentrations. J. Clin. Endocrinol. \& Metab. 64:51-58.

6. Quabbe, H. J. 1977. Chronobiology of growth hormone secretion. Chronobiologia. 4:217-246.

7. Quabbe, H. J., E. Schilling, and H. Helga. 1966. Pattern of growth hormone secretion during a 24 hour fast in normal adults. $J$. Clin. Endocrinol. \& Metab. 26:1173-1177.

8. Roth, J., S. M. Glick, R. S. Yalow, and S. A. Berson. 1963. Secretion of human growth hormone: physiologic and experimental modifications. Metab. Clin. Exp. 12:577-579.

9. Tannenbaum, G. S., and J. B. Martin. 1976. Evidence for an ultradian rhythm governing growth hormone secretion in the rat. Endocrinology. 98:562-568.

10. Reichlin, S. 1985. Neuroendocrinology. In Williams Textbook of Endocrinology. J. D. Wilson and D. W. Foster, editors. W. B. Saunders, Philadelphia. 492-567.

11. Clemmons, D. R., A. Klibanski, and L. Underwood. 1981. Reduction of plasma immunoreactive somatomedin-C during fasting in humans. J. Clin. Endocrinol. \& Metab. 53:1247-1250.

12. Berelowitz, M., M. Szabo, L. A. Frohman, S. Firestone, and L. Chu. 1981. Somatomedin-C mediates growth hormone negative feedback by effects on both the hypothalamus and pituitary. Science (Wash. DC). 212:1279-1281.

13. Thorner, M. O., J. Rivier, J. Spiess, J. L. C. Borges, M. L. Vance, S. R. Bloom, A. D. Rogol, M. J. Cronin, D. L. Kaiser, W. S. Evans, J. D. Webster, R. M. Macleod, and W. Vale. 1983. Human pancreatic growth hormone-releasing factor selectively stimulates growth hormone secretion in man. Lancet. i:24-28.

14. Wehrenberg, W. B., P. Brazeau, R. Luben, P. Bohlen, and R. Guillemin. 1982. Inhibition of the pulsatile secretion of growth hormone by monoclonal antibodies to the hypothalamic growth hormone releasing factor. Endocrinology. 111:2147-2148.

15. Kadish, A. H., R. L. Little, and J. C. Sternberg. 1968. A new and rapid method for the determination of glucose by measurement of rate of oxygen consumption. Clin. Chem. 14:116-131.

16. Furlanetto, R. W., L. E. Underwood, J. J. Van Wyk, and A. J. D'Ercole. 1977. Estimation of somatomedin-C levels in normals and patients with pituitary disease by radioimmunoassay. J. Clin. Invest. 60:648-657.

17. Knox, D. P., and D. G. Jones. 1984. Automated enzymatic determination of plasma free fatty acids by centrifugal analysis. $J$. Automatic Chem. 6:152-154.
18. Lloyd, B., J. Burrin, P. Smythe, and K. G. M. M. Alberti. 1978. Enzymatic, fluorimetric continuous-flow assays for blood glucose, lactate, pyruvate, alanine, glycerol and 3-hydroxy-butyrate. Clin. Chem. 24:1724-1729.

19. Veldhuis, J. D., and M. L. Johnson. 1986. Cluster analysis: a simple, versatile and robust algorithm for endocrine pulse detection. Am. J. Physiol. (Endocrinol. Metab. 13) 250:E486-E493.

20. Evans, W. S., A. C. S. Faria, E. Christiansen, K. Y. Ho, J. Weiss, A. D. Rogol, M. L. Johnson, R. M. Blizzard, J. D. Veldhuis, and M. O. Thorner. 1987. Impact of intensive venous sampling on the characterization of pulsatile GH release. Am. J. Physiol. (Endocrinol. Metab. 15) 252:E549-E556.

21. Mauras, N., R. M. Blizzard, K. Link, M. L. Johnson, A. D. Rogol, and J. D. Veldhuis. 1987. Augmentation of growth hormone secretion during puberty: evidence for a pulse amplitude-modulated phenomenon. J. Clin. Endocrinol. \& Metab. 64:596-601.

22. Johnson, M. L. and S. G. Frazier. 1985: Nonlinear least-squares analysis. Methods Enzymol. 117:301-342.

23. Steiner, R. A., J. S. Stewart, J. Barber, D. Koerker, C. J. Goodner, A. Brown, P. Illner, and C. C. Gale. 1978. Somatostatin: a physiological role in the regulation of growth hormone secretion in the adolescent male baboon. Endocrinology. 102:1587-1594.

24. Parker, D. C., L. G. Rossman, and D. F. Kripke. 1979. How fasting affects human growth hormone (hGH) rhythms to enhance release. Clin. Res. 27:75A. (Abstr.)

25. Dement, W., and N. Kleitman. 1957. Cyclic variation in EEG during sleep and their relation to eye movements, body motility and dreaming. EEG Clin. Neurol. 9:673-690.

26. Fisher, C., J. Gross, and J. Zuch. 1965. A cycle of penile erection synchronous with dreaming sleep. AMA Arch. Gen. Psychiat. 12:29-45.

27. Coccagna, G., M. Mantovani, F. Brignani, A. Manzini, and E. Lugaresi. 1971. Arterial blood pressure changes during spontaneous sleep in man. Electroencephalogr. Clin. Neurophysiol. 31:277-281.

28. Orr, W. C., H. J. Hoffman, and F. W. Hegge. 1974. Ultradian rhythms in extended performance. Aerosp. Med. 45:995-1000.

29. Oswald, I., J. Errington, and H. Lewis. 1970. Cyclic "on demand" oral intake by adults. Nature (Lond.). 225:959-960.

30. Levin, B. E., M. Rappaport, and B. H. Natelson. 1979. Ultradian variations of plasma noradrenaline in humans. Life Sci. 25:621628.

31. Tannenbaum, G. S., J. B. Martin, and E. Colle. 1976. Ultradian growth hormone rhythm in the rat: effects of feeding, hyperglycemia and insulin-induced hypoglycemia. Endocrinology. 99:720-726.

32. Tannenbaum, G. S., O. Rorstad, and P. Brazeau. 1979. Effects of prolonged food deprivation in the ultradian growth hormone rhythm and immunoreactive somatostatin tissue levels in the rat. Endocrinology. 104:1733-1738.

33. Tannenbaum, G. S. 1981. Growth hormone secretory dynamics in streptozotocin diabetes: evidence of a role for exogenous circulating somatostatin. Endocrinology. 108:76-82.

34. Aoki, T. T. 1985. Hormone-fuel interrelationships in normal, fasting, and diabetic man. In Joslin's Diabetes Mellitus. A. Marble, L. P. Krael, R. F. Bradley, and A. R. Christlieb, editors. Lea and Febiger, Philadelphia. 138-157.

35. Cahill, G. F., M. G. Herrera, A. P. Morgan, J. S. Soeldner, J. Steinke, P. L. Levy, J. A. Reichard, and D. M. Kipnis. 1966. Hormone-fuel relationships during fasting. J. Clin. Invest. 45:1751-1768.

36. Bougneres, P. F., E. Artavia-Loria, P. Ferre, J. L. Chaussain, and J. C. Job. 1985. Effects of hypopituitarism and growth hormone replacement therapy on the production and utilization of glucose in childhood. J. Clin. Endocrinol. \& Metab. 61:1152-1157.

37. Bratusch-Marrain, P. R., D. Smith, and R. A. DeFronzo. 1982. The effect of growth hormone on glucose metabolism and insulin secretion in man. J. Clin. Endocrinol. \& Metab. 55:973-982.

38. Felig, P., E. B. Marliss, and G. F. Cahill. 1971. Metabolism response to human growth hormone during prolonged starvation. $J$. Clin. Invest. 50:411-421. 
39. Fain, J. N., V. P. Kovacev, and R. O. Scow. 1965. Effect of growth hormone and dexamethasone on lipolysis and metabolism in isolated fat cells of the rat. J. Biol. Chem. 240:3522-3559.

40. Haymond, M. W., I. Karl, V. V. Weldon, and A. S. Pagliara. 1976. The role of growth hormone and cortisone on glucose and gluconeogenic substrate regulation in fasted hypopituitary children. J. Clin. Endocrinol. \& Metab. 42:846-856.

41. Merimee, T. J., P. Felig, E. Marliss, S. E. Fineberg, and G. F. Cahill. 1971. Glucose and lipid homeostasis in the absence of human growth hormone. J. Clin. Invest. 50:574-582.

42. Owen, O. E., P. Felig, and A. P. Morgan. 1969. Liver and kidney metabolism during prolonged starvation. J. Clin. Invest. 48:574-580.

43. Manson, J., and D. W. Wilmore. 1986. Positive nitrogen bal- ance with human growth hormone and hypocaloric intravenous feeding. Surgery (St. Louis). 100:188-197.

44. Oscarsson, J., and S. Eden. 1987. Secretory pattern of growth hormone $(\mathrm{GH})$ regulates fatty acid composition of phosphatidylcholine (PC) in plasma and liver of the rat. J. Endocrinol. Invest. 10(Suppl. 4). (Abstr.) p. 10.

45. Ekberg, S., A. Mode, M. Ritzen, and J-O. Jansson. 1987. A "feminine" secretory pattern of growth hormone $(\mathrm{GH})$ induces high serum levels of corticosteroid binding globulin (CBG). J. Endocrinol. Invest. 10(Suppl. 4). (Abstr.) p. 10.

46. Imaki, T., T. Shibasaki, K. Shizume, A. Masuda, M. Hotta, Y. Kiyosawa, K. Jibiki, H. Demura, T. Tsushima, and N. Ling. 1985. The effect of free fatty acids on growth hormone (GH)-releasing hormonemediated GH secretion in man. J. Clin. Endocrinol. \& Metab. 60:290-293. 